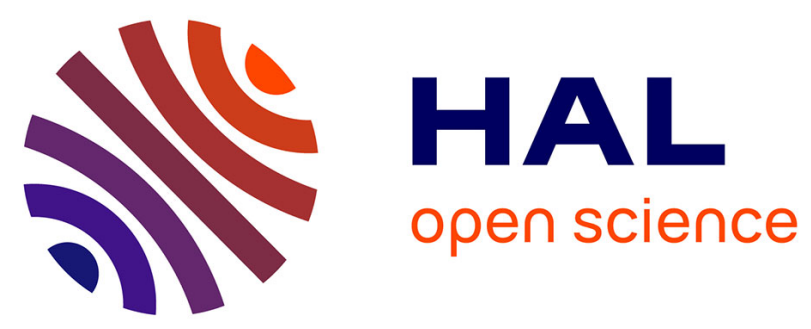

\title{
Does a Master Always Write for His Students? Some Evidence from Old Babylonian Scribal Schools
}

\author{
Christine Proust
}

\section{To cite this version:}

Christine Proust. Does a Master Always Write for His Students? Some Evidence from Old Babylonian Scribal Schools. Scientific Sources and Teaching Contexts throughout History: Problems and Perspectives, Springer, pp.69-94, 2014, 10.1007/978-94-007-5122-4_4 . hal-01139613

\section{HAL Id: hal-01139613 https://hal.science/hal-01139613}

Submitted on 7 Apr 2015

HAL is a multi-disciplinary open access archive for the deposit and dissemination of scientific research documents, whether they are published or not. The documents may come from teaching and research institutions in France or abroad, or from public or private research centers.
L'archive ouverte pluridisciplinaire HAL, est destinée au dépôt et à la diffusion de documents scientifiques de niveau recherche, publiés ou non, émanant des établissements d'enseignement et de recherche français ou étrangers, des laboratoires publics ou privés. 


\title{
Does a master always write for his students? Some evidence from Old Babylonian scribal schools
}

\author{
Christine Proust, Laboratoire SPHERE (CNRS \& Université Paris Diderot)
}

\section{Introduction}

Ancient Mesopotamia has given us more than two thousand clay tablets containing mathematical texts. For the large majority (more than $80 \%$ ), these tablets were written in the Old Babylonian period, that is, between 2000 and $1700 \mathrm{BC}^{1}$. This mathematical corpus has been divided into two large categories, tablets written by young students, and the rest ${ }^{2}$. The school tablets, little studied as such until recently, have often lain forgotten in museum storerooms and have only been published systematically in recent years ${ }^{3}$. Today they represent a considerable part of the known mathematical documentation. Other mathematical texts, those Neugebauer calls "problem texts", can be described in a very approximate way as "erudite texts", as opposed to the texts written by learners, which I refer to in what follows as "elementary school texts". The context in which the tablets containing the erudite texts were produced is more difficult to identify than that of the school tablets, due to their typology being less characteristic and above all due to the fact that the provenance of these tablets is generally unknown ${ }^{4}$. Indeed, the majority of them were bought from antiquities traders by European and American museums in the 1920s and 1930s. However, some groups of tablets which come from legal excavations do benefit from a relatively clear archeological context. Examples of this are groups found at Nippur and Ur in southern Mesopotamia, at Tell Harmal and Tell Haddad in the kingdom of Eshnunna (Diyala Valley, in the north of Mesopotamia); at Susa in

\footnotetext{
${ }^{1}$ Note on the dates: All the dates given in this chapter are "BC". The dating follows "middle chronology", according to which the dates of Hammurabi's reign are 1792-1750; this system, although contested (Gasche et al, 1998), is the most widely used by historians of the Ancient Near East. Note on the sources: the information on the tablets quoted in this chapter (physical description, references, photographs, copies, transliterations, translations) are available on the Cuneiform Digital Library Initiative (CDLI) website. The statistics come from the CDLI website database, completed by data from my own unpublished database. To July 2011, the CDLI has identified 1826 mathematical tablets, so is a relatively complete inventory of mathematical sources known today. We must, however, add to this total further unpublished tablets kept at the Oriental Institute of the University of Chicago (approximately 200 school tablets from Nippur), and those unearthed at Mari (140 scholarly tablets), so a total approaching 2200 tablets. Of these, approximately 1850 date from the Old Babylonian period.

2 These categories were described by Neugebauer and Sachs $(1945,1)$ thus, "the mathematical texts from ancient Babylonia fall into two main categories: 'table-texts' and 'problem-texts.' " Later archeological research has shown that the "table-text" category essentially covers Old Babylonian learners output.

${ }^{3}$ (Veldhuis 1997, Robson 2001, Robson 2002, Friberg 2000, Proust 2007, Proust 2008b).

4 The vast majority of the known elementary school tablets come from Nippur, a site that has been excavated under relatively well-controlled conditions by American expeditions from Universities of Pennsylvania and Chicago. As a result, most of the school tablets have an identified origin (Nippur, in this case). Another factor is linked to the antiquities market. Less coveted by the antique dealers as they are often in poor condition and having unattractive content, the school tablets are traded less than the scholarly tablets. As a result, a greater proportion of them come from legal excavations.
} 
Elam, in the west of modern Iran ${ }^{5}$. The fact that interests us here is that, when their provenance is known, the tablets containing erudite texts were found along with elementary school tablets. The same is true for literary tablets, which are generally found in the same location as those that were used for elementary level lexical exercises.

As a consequence, cuneiform mathematical texts from the Old Babylonian period are clearly the result of the activities of scribal schools and, in this sense, emanate incontestably from a "teaching context". Mathematicians in the Old Babylonian period were primarily masters in scribal schools. J. Høyrup describes these mathematician/teachers thus:

The mathematical texts are school texts. [...] their authors [...] were teachers of computation, at times teachers of pure, unapplicable computation, and plausibly specialist of this branch of scribal education; but they remained teachers, teachers of scribal school students who were later to end up applying mathematics to engineering, managerial, accounting, or notarial tasks. (Høyrup 2002, 8)

As the mathematical texts were written by masters does it follow that they were always written for teaching purposes? A positive response is more or less explicitly assumed in most of the publications devoted to cuneiform mathematics. Mathematical texts are generally considered as evidence of pedagogical activity, meaning they are assumed to have been written either by students or for students. My goal is to show the simplistic nature of such a narrow alternative.

First of all, it should be noted that the context of scribal schools is unique to the Old Babylonian period, and that it cannot be applied identically to older periods, notably the Sargonic period (2340-2200) and the Third Dynasty of Ur (2100-2000), nor to more recent periods, notably the Hellenistic period (323-63). These archaic and later periods have given us a small mathematical corpus produced under quite different contexts, which we will not address here?

Turning now to the Old Babylonian corpus, the problems posed to historians in the contextual analysis of elementary school texts are not the same as those posed by the erudite texts. The elementary school texts are by definition the product of teaching activities, but so far their context is not transparent. They are generally perceived to be simple, easy and even relatively puerile texts, created for pedagogical purposes. It is the misleading synonymy of "elementary", "simple" and "puerile" that I take issue with. The erudite texts, for their part, are generally understood to be expressing a type of didactic discourse the masters addressed to their students. The assumption that a mathematical text written by a master is a teacher's guide, may lead to misunderstanding the meaning of certain texts ${ }^{8}$.

In this chapter, I am going to focus on three groups of Old Babylonian-period clay tablets, each group will be the subject of a section. The first is a group of elementary school tablets from Nippur $(\S 1)$, numbering around a thousand tablets from the same source, having the same dating, and relatively clear archeological context. The teaching situation in which these writings were produced is relatively well known. It is documented in Sumerian literary texts,

\footnotetext{
5 (Neugebauer 1935-7, Neugebauer and Sachs 1945, Thureau-Dangin 1936, Goetze 1951, Bruins and Rutten 1961, Al-Rawi and Roaf 1984, Baqir 1950a, Baqir 1950b, Baqir 1951, Baqir 1962).

${ }^{6}$ [Problem texts] are school products intended to illustrate the rules for dealing with problems which are properly called 'algebraic'.'(Neugebauer and Sachs 1945, 1).

7 In (Bernard and Proust 2008) there are comments on the various contexts through the evocation of the history of reciprocal tables - texts that have lasted millennia without great modification, but whose use has changed considerably over time.
}

\footnotetext{
${ }^{8}$ I think this is the case for the interpretations that were given for CBS 1215, which deals with the inversion method of regular numbers, on Plimpton 322, which deals with Pythagorean triples, and series texts (see Britton et al. 2011; Proust forthcoming-a, Proust forthcoming-a).
} 
in abundant archeological data and in the school texts themselves. Many studies of this rich and varied documentation are available to historians today ${ }^{9}$. One of the most interesting aspects of the Nippur tablets is precisely that they form a remarkably homogenous, coherent and structured group. In section 1, I endeavor to show how each piece of text fits within the whole and that the meaning of a text is only understandable in relation to other texts. Far from being puerile texts, these school tablets reveal a highly-sophisticated system, developed for purposes other than education.

The second group studied in chapter $2(\S 2)$ is composed of procedure texts (lists of problem statements followed by their resolution and catalogues (lists of problem statements with no indication of their resolution). At first sight, the written style of these texts evokes that of a master addressing his students. To a certain degree they could have a similar function to that of a school textbook. However, I will show that teaching was probably not the only objective pursued by the authors of the catalogues.

The third group is the series texts $(\S 3)$, which are lists of thousands of problem statements, written on a succession of tablets and numbered like pages in a book. I show that in this case, one can seriously doubt that such texts were written for teaching purposes. In writing these vast series texts, the scribal school masters were visibly not addressing their students, but their peers.

These three groups show a certain internal coherence, which allows the texts to be placed in an environment rich in textual information. The meaning of each text is therefore enhanced by other texts in the group it belongs to. Analysis of these groups allows us to show that an elementary school text was not always puerile; that a text written for teaching could at the same time serve other purposes and that a text written by a master did not always have an educative objective. The contrasting analysis of these three groups thus allows me to highlight the contextual diversity of both the production and the usage of the texts, all of which nevertheless derive from Old Babylonian-period scribal schools in southern Mesopotamia.

\section{1- School tablets and school texts}

In this section I would like to draw attention to the fact that the school tablets, that is, the documents produced by student scribes, do not always contain texts designed by the masters for learning. The following examples show that, in certain cases, the texts clearly reflect pedagogical intent, but in other cases, the texts were originally developed for other purposes.

Before addressing the output of scribal school students, I should briefly present these schools.

\section{Scribal schools}

Although the existence of scribal schools was identified by Hermann Hilprecht ${ }^{10}$ at the beginning of the $\mathrm{XX}^{\text {th }}$ century, studies have only recently focused specifically on the description of the teaching itself and the consequences that precise knowledge of the organization and operation of scribal schools could have on the interpretation of texts. Work carried out by Niek Veldhuis is probably the most innovative on this point. Veldhuis studied Nippur school tablets

\footnotetext{
${ }^{9}$ See the bibliography given in footnote 3 , and (Proust 2011).

${ }^{10}$ (Hilprecht 1906).
} 
and has been able to recreate the elementary school curriculum followed by young scribes in this city's schools ${ }^{11}$. Moreover, Sumerian literature, evidenced mainly at Nippur, brings lively and detailed accounts of life in the schools ${ }^{12}$. In return, some literary sources are themselves seen in a new light through the relatively accurate knowledge of the teaching context from which they come. So Veldhuis proposes a new reading of the collections of proverbs which, according to him, are not only "wisdom texts" as generally stated, but are part of the training curriculum for scribes, being used above all in learning the Sumerian language. It should be remembered that in the Old Babylonian period, Sumerian was the scholastic language, but it was no longer spoken by the population at large. Sumerian lexical lists, proverbs and literary texts form a coherent whole, a kind of network through which the proverbs take all their meaning.

In practice this means that we may try to look at lexical and literary texts as a synchronic corpus. The educational texts from Nippur -be they literary, lexical, or proverbial- belong together in a single educational system. They share a functional, physical, historical, and presumably cognitive background. Ideally, understanding of a single composition involves understanding of the whole corpus and the structure of that corpus. [...] This way of looking at texts is hardly new in Assyriology. It finds a parallel in the so-called archival approach to administrative texts. (Veldhuis 2000, 389).

A similar analysis was developed by Herman L. J. Vanstiphout ${ }^{13}$ on a literary composition presenting itself as a hymn to Isin king Lipit-Eshtar (reign 1934-1924). The meaning of this hymn becomes clear when one considers it was the first literary text addressed by young scribes at Nippur during their training. In fact the text presents a succession of grammatical structures for learning Sumerian verb forms. It is noteworthy that the tablets on which the extracts of this text are found often have the elongated form characteristic of supports used at the beginning of the advanced training level, which of course came after the elementary level.

An "archival" approach, taking Veldhuis's expression (see the quotation above) ${ }^{14}$, can be applied to the mathematical texts and produce interesting results as it captures the originality of certain teaching concepts used in the scribal schools. The example of surface calculations is instructive in this regard. Indeed, the surface calculation exercises found at Nippur can only be understood if one takes into account their relationship to other mathematical school texts from the same site (see previous paragraph).

The Nippur site was excavated in a systematic way by teams of American archeologists from the University of Pennsylvania for the first campaigns (1888-1900), then by teams from the Universities of Pennsylvania and Chicago for the latest (1948-1990). These expeditions led to the discovery of thousands of school text tablets, found mostly in the relatively small zone known as "Tablet Hill" where the scribal schools must have been located". These "archives" date for the most part from the reign of Hammurabi's son, Samsu-Iluna (1749-1712). Where the archeological context of the school text tablets is known, it shows that they were thrown

\footnotetext{
11 (Veldhuis 1997).

${ }^{12}$ Several authors have drawn attention to the fact that the literary texts used for training did not objectively reflect the reality of schools but rather reflected the ideology particular to the scribal milieu of Nippur

(Michalowski 1987, 63 ; George 2005). Some literary texts, however, contain many details on the school curriculum that are confirmed by independently obtained data, and are therefore valuable sources of information.

${ }^{13}$ (Vanstiphout 1979).

${ }^{14}$ This method consists in analyzing the text, not in isolation, but as an element in a collection of documents found at a precise archeological locus. See on this subject (Veenhof 1986).

${ }^{15}$ The best documented of the scribal schools at Nippur is "House F", whose contents were analyzed by (Robson 2001).
} 
away after use and recycled as construction material. These tablets are divided today between several collections kept in Philadelphia (the collection includes approximately 500 mathematical tablets), in Istanbul (312 mathematical tablets), in Jena (79 mathematical tablets), Chicago (approximately 200 mathematical tablets), and in Baghdad ${ }^{16}$. These collections total over a thousand pieces, of which around 900 have been published. They are therefore quite representative of Nippur scribal school output in the field of elementary mathematics during the first half of the $18^{\text {th }}$ century BC.

Elementary school tablets from Nippur are easy to recognize as they have specific physical characteristics which differentiate them from other mathematical tablets. Four types of elementary school tablet have been identified at Nippur: those of type I are large, multi-column tablets; those of type II contain a master's example and the pupil's copy on the obverse and the transcription of a memorized text on the reverse; type III are small elongated tablets containing a short extract and type IV are small lenticular or square tablets ${ }^{17}$.

Another characteristic feature of elementary school tablets is that they contain stereotypical texts almost identical to those found in all Mesopotamian scribal schools. From studying these we can reconstruct the scribes' mathematics training curriculum, which, broadly, was made up of an elementary, an intermediate and an advanced level. The first two levels are relatively well known thanks to information provided by physical evidence, the most important being in relation to the typology of the tablets. The advanced level is much less documented (see $\$ 2$ ). The elementary and intermediate stages of the mathematics curriculum are represented as follows:

\begin{tabular}{|c|c|c|c|}
\hline Texts & $\begin{array}{c}\text { Number of tablets were } \\
\text { these texts are identified }\end{array}$ & Level & Tablet type \\
\cline { 1 - 2 } Metrological lists & 187 & Elementary & I, II, III \\
\hline Metrological tables & 161 & & IV \\
\hline Numerical tables & 417 & Intermediate & \\
\hline Exercises & 35 &
\end{tabular}

Table 1: mathematics curriculum at Nippur

The metrological lists are the enumeration of measurements of capacity, weight, surface and length, in that order. The metrological tables enumerate the same items as the lists but give for each measurement a correspondence to an abstract number written in sexagesimal place value notation, characteristic of cuneiform mathematics ${ }^{18}$. The numerical tables are made up of reciprocal tables, multiplications, squares, square roots and cube roots; they are written entirely in a floating point notation. The exercises focus mainly on calculating reciprocals, multiplication and surfaces ${ }^{19}$.

Were all these texts designed for teaching? The answer seems clear (and positive) to me for the calculation exercises, but less clear for the metrological lists and numerical tables.

\footnotetext{
${ }^{16}$ These tablets are for the large part published (Proust 2007, Proust 2008b, Robson 2001) or are on the way to being published.

${ }^{17}$ For more details, see (Veldhuis 1997, Robson 2001, Proust 2007, Proust 2008b).

${ }^{18}$ This is a "floating" sexagesimal place value notation, meaning that is does not indicate orders of magnitude. A detailed description of the metrological lists and tables, as well as positional notation can be found in Proust $2009 \mathrm{~b}$ (article on line).

${ }^{19}$ See (Proust 2007, ch. 6 and 7).
} 


\section{School text tablets containing didactic texts}

Among the documents that correspond to the intermediate level, are found ten or so tablets containing a calculation for the surface of a square, carried out using the same model: a short text is written in Sumerian in the lower right-hand corner, and several numbers are placed one under the other in the upper left-hand corner. These type IV tablets have the characteristic cushion shape of intermediate-level school text tablets at Nippur. Tablet UM 29-15-192, a copy and transcription of which are given below is an example ${ }^{20}$.

\section{Transcription}

251)

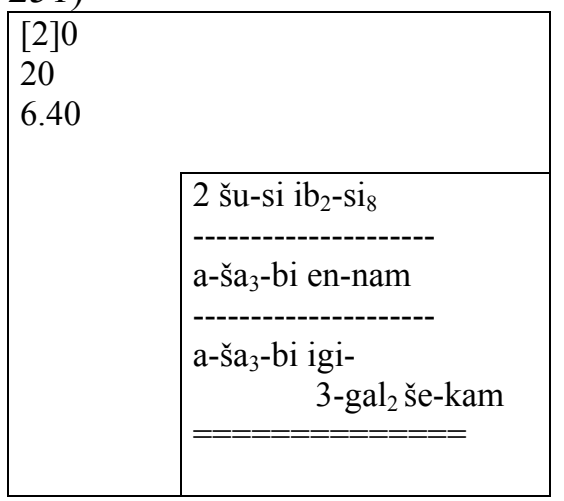

\section{Translation}

$20 \times 20=6.40$

2 šu-si the side (of the square).

What is the surface?

Its surface is $1 / 3$ še copy (Neugebauer \& Sachs 1984,

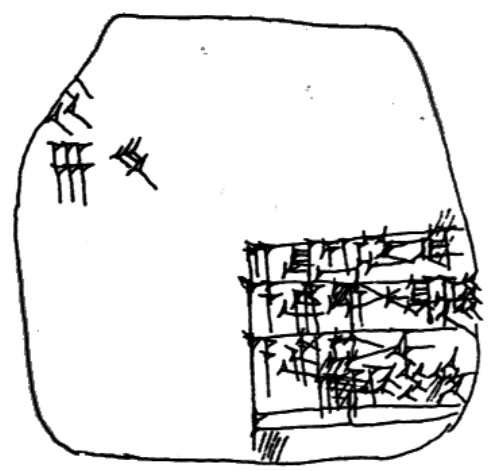

Table 2: tablet UM 29-15-192

This tablet is striking in that the layout of the text is in two zones. On closer inspection we notice that the numeric data in the two zones is not of the same nature: the data in the lower right-hand corner is metrological (side and surface), written in accordance with the rules of the metrological lists; the data in the upper left-hand corner is made up of abstract numbers of the same type as those found in the numerical tables. More interesting still is that there is a correspondence between the numeric data in the two areas, and that this correspondence is exactly that which the metrological tables give. For example, the metrological table of lengths establishes that the measurement 2 su-si (approx. $3 \mathrm{~cm}$ ), which we read at the bottom on the left-hand side, corresponds to the positional number 20 . And this is exactly the same number as is written in the top left-hand corner. The product of the calculation $20 \times 20$, necessary for the evaluation of the surface is given in the 'by 20 ' multiplication table. The result is the number 6.40 which is placed under the factors 20 . The metrological table for surfaces establishes that the number 6.40 corresponds to a surface of $1 / 3$ še, which is that given in the text at the bottom. So the two number systems used in the two zones on the tablet refer to the two number systems in the metrological tables. The calculation of surfaces is based on the transformation of metrological data into "floating" positional numbers to allow the multiplication to be carried out easily, then by reading the metrological table in reverse to obtain the result as a measurement of surface. Note that mental evaluations of orders of magnitude are necessary in all stages of this process. Calculation using abstract numbers greatly facilitates the passage of linear dimensions into bi-dimensional elements; the calculation of the product would be extremely problematic if units of measurement were involved because of the irregularities of metrology. There is, therefore, in the calculation practiced by the scribes, no conversion from one unit to another, contrary to what the reading of the tablet alone, isolated from its contextual environment, may suggest ${ }^{21}$.

${ }^{20}$ Tablet UM 29-15-192 comes from Nippur and is kept in Philadelphia; it is published in (Neugebauer and Sachs 1984, 251).

${ }^{21}$ This last interpretation, based on the idea that surface and volume calculations use unit conversions, is largely referred to in the publications on this subject. I have explained in detail the reasons for my disagreement with 
But the reach of these results goes much further: to understand the methods taught to young scribes is also to understand the fundamentals on which the scholars relied. As a result, the elementary school texts provide historians today with the opportunity to interpret advanced mathematical works not using their own algebraic tools, but rather with methods forged by the scribes themselves.

Tablet UM 29-15-192 is a school text in the sense that it was written by an apprentice scribe as he learned mathematics. In addition, its content has a clearly didactic function: the text is designed to teach precise mathematical knowledge. As the layout of the text on the tablet shows, the learner is guided by a master whose intentions are perceptible: to explain the relationship between abstract positional numbers and metrological data in surface calculations, and using this relationship in a real calculation.

\section{School texts that are not puerile}

If we now consider metrological tables (or multiplication tables), the analysis is a little different. As indicated above, the versions of the texts found at Nippur come from elementary school tablets. But were these tablets created especially for teaching? Several clues seem to indicate that this is not the case. On one hand, the oldest reciprocal tables, dating from the end of the $3^{\text {rd }}$ millennium were written on tablets different in appearance to the Old Babylonian tablets. Indeed, they are of much higher quality: fine clay and with very small, uniform writing. They do not appear to have been produced by inexperienced young apprentices, but rather by expert hands. The oldest versions of the tables were not, perhaps, written for elementary teaching. On the other hand, metrological and numerical tables are also documented, other than those from Nippur, as being written on types of support other than those used in teaching, as are type I, II and III tablets at Nippur (see table 1 above). An example is the beautiful AO 8865 Prism kept at the Louvre and containing metrological tables, tables of squares, square roots and cube roots ${ }^{22}$. The prism is transpierced by an axial hole, around which the prism can be rotated to change the view; the tablet seems therefore to have the function of a reference document and not only in school exercises. It is clear, moreover, that the tables, which were assimilated by the young scribes at Nippur at the beginning of their mathematical training, also served as data sets that would be brought into use as a calculator throughout their career. They are, therefore tools which were not necessarily initially made for teaching but that were used in teaching, a little like the trigonometry tables which modern schoolchildren carried in their schoolbag before the era of the first electronic calculators.

In fact, the lists and metrological tables probably originally had, at the time of their design, an essentially normative function. They were developed as part of policies of large scale standardization and unification of systems for weights and measures undertaken by the first centralized states in Mesopotamia in the second half of the third millennium ${ }^{23}$. These normative texts were produced by a bureaucracy with the objective of economic and social regulation. The normative texts seem to have been re-used in education, and set out by the masters in a particular way on the school text tablets (of types I, II and III at Nippur), to allow their assimilation and probably memorization by the future scribes.

\footnotetext{
this interpretation in (Proust2008a). A recent example where the surface exercises are explained, in an uncontextualized way, by the conversion of units is found in (Robson 2008, 8-12).

22 (Proust 2005).

${ }^{23}$ For a detailed analysis of the normative character of the metrological texts, see (Proust 2009b).
} 
These remarks show the ambiguity of the term "school text": a tablet could be a school text, that is, written by a student scribe, without the text it contains being didactic, at least in its original intent. These distinctions between the text and its support on one hand, and between the creational context and the context of its use on the other, here echo those made by AnneMarie Chartier (c. xxx this volume) regarding the use of Psalters in learning to read in the seventeenth century. Like metrological lists, Psalters were not created with the intention of teaching, but were used for this purpose (see p. $\mathrm{xxx}$ of this work).

Another ambiguity comes from the fact that the words "school texts" are generally applied by Assyriologists to all texts used for the learning of cuneiform writing and calculation. However this term carries the implication of the initial training of young people, sometimes children, who did not already know how to read or write. This was the case in Old Babylonian scribal schools. But the texts used in the Hellenistic period for learning cuneiform at temples in Uruk and Babylon were certainly not addressed to children taking their first steps in writing and arithmetic, but to young Aramaic speaking students, already fluent in written and spoken Greek, learning the difficult cuneiform script and the dead languages (Sumerian and Akkadian) it conveyed, with the intention of acceding to scholarly professions such as medicine and divination (see chapter $\mathrm{xxx}$ by P. Clancier, $\mathrm{p} . \mathrm{xxx}$ ). Although the texts used in these two cases were often the same and certain elements of the Old Babylonian tradition were passed down from one generation to the next for more than the 1500 years that separate the two periods, it is clear that in the Old Babylonian and the Hellenistic periods, the words "school text" referred to completely different actors and teaching practices.

This section has shown, through several examples, the importance of differentiating between the tablets and the texts that the tablets contain. It has also shown that "school" texts are neither necessarily "didactic" nor "puerile". The school text tablets from Nippur sometimes contain didactic texts (see the example of the surface calculation); sometimes contain normative texts of non-scholastic origin (see the example of the metrological texts). It is equally possible that some school texts, written originally for teaching purposes could later become scholarly texts belonging to a cultural heritage rather than an educational curriculum (we can think of certain Sumerian literary texts). Finally, the same texts could have been used, at certain times, in the initial training of scribes when they were still children, and, at other times in the specialized teaching of young scholarly professionals (see the example of the savants of Uruk and Babylon in the Hellenistic period).

\section{Texts written by masters for advanced teaching}

In the elementary school texts, the historian has a wealth of structured documentation having relatively clear archaeological context. For the "erudite" texts ${ }^{24}$, the situation is far from being as favorable, because, as is indicated in the introduction, most of the known erudite mathematical texts come from illegal excavations. Their dating and geographical provenance can only be assessed from indirect evidence. Lexical and epigraphical criteria allow Old Babylonian period, tablets to be clearly distinguished from later periods, notably the Hellenistic period. Within the large corpus of Old Babylonian texts, one can differentiate groups having different origins and dates. The first philologist to discern regional differences was Albrecht Goetze $^{25}$. A linguistic study of Akkadian terminology and graphics allowed the author to make

\footnotetext{
${ }^{24}$ I use the term "erudite" here in contrast to "elementary school" (see the introduction of this chapter). This term refers to teaching texts destined for advanced student or pieces of pure erudition.

${ }^{25}$ (Goetze 1945).
} 
a distinction between northern and southern texts, early and later texts; and in some cases, he was able to define homogeneous groups probably originating from the same site. The "erudite" texts bear witness to several different mathematical traditions, the three most significant, but not the only ones, being those of south Sumeria-Akkadia, the kingdom of Eshnunna and Susiana. According to J. Høyrup, who extended Goetze's classification (Høyrup 2002, ch. 9), the different communities of scribes cultivated specific mathematical interests and developed different methodological approaches. The diversity of practices is also evident in the typology of the tablets, the language (Sumerian and Akkadian) and the writing techniques used. The examples studied in this chapter probably all come from the Mesopotamian plain (from Ur to Sippar) and as a result I will focus principally on information on this area.

A first series of physical clues comes from the study of literary tablets. A typological analysis of the tablets from scribal schools at Nippur was carried out by S. Tinney ${ }^{26}$. This author differentiates tablets written in a single column (type $S$ ), corresponding to the beginning of the advanced curriculum, from tablets written in multiple columns (type $\mathrm{M}$ ), corresponding to the writings of advanced students and masters. Although based on literary documentation, this typology probably has meaning for mathematical texts because the artifacts produced by the schools show that the type of tablet depends on the level of teaching and the didactic situation, not the genre of text. The typology of tablets used at Nippur was not always adopted by scribes in schools in other cities. However, it does provide clues which, used with caution and cross-referenced with other information, can help clarify contextual elements of documents of unknown provenance. This section will be devoted to texts written on type S tablets, and Section 3 to texts written on type M.

The three texts examined in this section were selected partly because they are good examples of Old Babylonian period mathematics teaching texts and partly because they are closely interconnected. For ease of reference, the three tablets considered in this section are lettered (A, $\mathrm{B}$ and $\mathrm{C}$ ). The concordance with the museum (here, the Yale Babylonian Collection) inventory numbers is as follows:

\begin{tabular}{|c|c|c|c|c|}
\hline & $\begin{array}{c}\text { Museum inven- } \\
\text { tory number }\end{array}$ & $\begin{array}{c}\text { Category of } \\
\text { text }\end{array}$ & $\begin{array}{c}\text { Type of tab- } \\
\text { let }\end{array}$ & Origin \\
\hline A & YBC 4663 & Procedure text & $\mathrm{S}$ & $\begin{array}{c}\text { Antiquities } \\
\text { Market }\end{array}$ \\
\hline B & YBC 4662 & Procedure text & $\mathrm{S}$ & $\begin{array}{c}\text { Antiquities } \\
\text { Market }\end{array}$ \\
\hline C & YBC 4657 & Catalogue & $\mathrm{S}$ & $\begin{array}{c}\text { Antiquities } \\
\text { Market }\end{array}$ \\
\hline
\end{tabular}

Table 3: concordance

\section{Two procedure texts: the masters teach}

Tablet A (YBC 4663) is very elongated and inscribed in a single column; the text ends on the reverse with a line, followed by a large blank space (see plate, figure 1). The origin of the tablet is unknown, but Goetze classified it in the southern groups. It contains a suite of 8 resolved problems on the digging of a trench, each problem is written in a section delimited by horizontal lines. The parameters of problems 1 to 6 (data and unknowns) are the dimensions of the trench (length, width and depth), its base, the volume of earth extracted, the number of work-

\footnotetext{
${ }^{26}$ (Tinney 1998, 46; Tinney 1999).
} 
ers necessary to dig the trench ${ }^{27}$, each worker's daily task, that is, the volume of earth assigned to them to be dug each day, their daily wage, their total wages (wages are expressed in weights of silver). All these parameters are linked by the simple relationship:

$$
\text { total wages }=\text { daily wage } \times(\text { length } \times \text { width } \times \text { depth }) / \text { daily task }
$$

The first problem gives values for the following parameters: the length, the width, the depth, the task (the volume assigned each day to each worker) the workers' daily wage. It requires the calculation of: the base, the volume, the number of workers necessary and the total wages. The resolution procedure is explained. The next problems (2-6) are variations that consist in carrying out circular permutations between given and unknown parameters. Problems 7 and 8 also offer variations of the same situation, but they are more complex as the data relates to linear combinations of length and width, leading to what we call today a quadratic problem. The numeric values in the 8 problems are always the same. The group forms a coherent structure and progressively increases in difficulty.

Meticulous examination of the text shows how the resolution of the problem employs the arithmetical tools taught in the elementary levels. Consider for example the first problem statement, for which the translation is as follows ${ }^{28}$ :

1. A trench. 5 ninda is the length, $1 \frac{1}{2}$ ninda the width, $1 / 2$ ninda its depth, 10 gin $_{2}$ the volume of assignment (for each worker), 6 še (silver) [the wages of a hired man].

2. The area, the volume, the number of workers, and the (total expenses in) silver what? You, in your procedure,

3. The length and the width multiply each other. This will give you 7.30.

4. $\quad 7.30$ to its depth raise. This will give you 45 .

5. The reciprocal of the assignment detach. This will give you 6. To 45 raise. This will give you 4.30

6. $\quad 4.30$ to the wages raise. This will give you 9. Such is the procedure.

Before examining this short text in detail, a few comments are in order. Firstly, the problem statement is written in Sumerian (standard font in the translation above), and the resolution procedure is written in Akkadian (italics above). Then, we notice that in the problem statement (lines 1-2), the data is expressed as concrete measurements, with units of measurement in accordance with the standards in the metrological lists, but only abstract numbers appear in the resolution procedure (lines 3-6). These observations suggest that, as in the case of the surface calculation referred to on tablet UM 29-15-192 mentioned above, there has been a process of conversion of metrological data into abstract numbers according to the correspondence established in the metrology tables. It is indeed the case, as shown by the correspondences below ${ }^{29}$.

$\begin{array}{llll}\text { length: } & 5 \text { ninda } & \rightarrow 5 & (\text { table L) } \\ \text { width: } & 11 / 2 \text { ninda } & \rightarrow 1.30 & (\text { table L) } \\ \text { depth: } & 1 / 2 \text { ninda } & \rightarrow 6 & (\text { table Lh) } \\ \text { daily task: } & 10 \text { gin }_{2} & \rightarrow 10 & (\text { table S) } \\ \text { wage: } & 6 \text { še } & \rightarrow 2 & (\text { table P) }\end{array}$

\footnotetext{
${ }^{27}$ It is assumed here that, by default, the work lasted one day: other texts lead to the belief that the work lasted 9 days (see YBC 4657 and YBC 4662 quoted later and Neugebauer and Sachs 1945, 74), and therefore it is the number of workers $\times$ days ( 30 workers for 9 days).

${ }^{28}$ I use standard font for the parts translated originally from Sumerian and italics for the parts written in Akkadian.

${ }^{29}$ One can refer to the metrological data tables in their entirety on the CDLI website (Proust 2009b). The arrows represent the "reading" of the tables, that is to say the correspondence established by the metrological tables. These are referred to, in brief, as follows: "table L" means the length measurement table, "table Lh " means the height measurement table; "table S" means the surface measurement table; "table P" refers to the weight measurement table. For more details on the calculation of volumes (units, using the height table and surface tables for volumes), see (Proust 2008a).
} 
The calculation, that is to say, the sequence of multiplications and inversions described in the procedure, is carried out on the abstract numbers in a floating-point notation ${ }^{30}$.

$\begin{array}{lllll}\text { base: } & 5 \times 1.30=7.30 & \rightarrow 71 / 2 \text { sar } & (\text { table S) } & \text { line } 3 \\ \text { volume: } & 7.30 \times 6=45 & \rightarrow 45 \operatorname{gin}_{2} & (\text { table } S) & \text { line } 4 \\ \text { workers: } & 45 / 10=45 \times 6=4.30 & \rightarrow 4\left(\mathrm{ges}^{2}\right) 3(\mathrm{u}) & 4 \times 60+30 & \text { line } 5 \\ \text { total wages: } & 4.30 \times 2=9 & \rightarrow 9 \operatorname{gin}_{2} & (\text { table P) } & \text { line } 6\end{array}$

The final step, omitted in this section but present in other sections of the tablet, is to convert the abstract numbers into concrete measurements by using the metrological tables in reverse (see $\S 1$ ).

The interpretation above is limited to the actual calculation. But another, more geometric aspect is reflected in the Akkadian vocabulary of the procedure, notably through the use of several different terms for multiplication (that I've translated by the verbs "to multiply" and "to raise"). This shows not only the precise nature of the calculation necessary to solve the problem, but also explains, by allusion to geometric figures what the meaning is of each of the operations. This demonstrative aspect of Babylonian mathematical procedures, perceptible in the vocabulary chosen by the scribes, was discovered by Jens Høyrup and developed in particular in (Høyrup, 2002).

Analysis of the above calculations shows that the text's authors were steeped in the elementary knowledge taught in scribal schools. It is clear that metrological tables were used to carry out the calculations. This usage is confirmed by the fact that the measurement/abstract number correspondences recorded on tablet A coincide perfectly with the metrological tables. One can add that, as noted above, metrological and numerical tables of the type found in abundance at Nippur have also been found in most sites in the Near East that housed former scribal schools. Tables identical to those found at Nippur have, for example, been recorded at Ur, Uruk, Larsa, Sippar, Kish, Ishchali, Mari, and even Ugarit. This suggests therefore, that the computational tools that can be recreated from the Nippur documents were widely used elsewhere. This is probably the same distribution vector, through scribal schools, as the standardized metrology developed in southern Mesopotamia at the end of the third millennium.

While it is very likely that this tablet is a result of activity at scribal schools, like all mathematical texts of the Old Babylonian period, the exact nature of these activities remains unclear. Firstly, let us remember an important detail: it is an elongated tablet written in a single column, i.e. a type $\mathrm{S}$ tablet according to Tinney's classification. And, we have seen that tablets of this type at Nippur are characteristic of intermediate level learning and the beginning of the advanced level. This stage corresponds, in the field of literature, to learning the basic structures of Sumerian, and in the field of mathematics to learning techniques used in solving problems on surfaces and volumes. Also note that these short, simple problems provide an opportunity to use, one after the other, direct and reverse reading of all the metrological tables, carry out surface and volume calculations, multiplications and inversions. The entire repertoire of elementary calculation is presented in a systematic way. This didactic progression presents a certain analogy to the repertoire of verb forms presented in the hymn to LipitEshtar evoked above. This suggests that it is a text designed specifically for teaching mathematics, written by a master or possibly copied by a student relatively advanced in his studies.

Several tablets closely related to the one we have just examined provide an information-rich textual environment. Firstly, the Yale collection contains another procedure tablet (designated $\mathrm{B}$ in the following), very close to Tablet $\mathrm{A}$ in its inventory number, its appearance, its content and its structure. Like tablet A, B is a type $\mathrm{S}$ tablet, whose problems relate to a trench of the

\footnotetext{
${ }^{30}$ The following equalities must comprise a modulus factor of $60 \mathrm{n}, \mathrm{n}$ entirely positive or negative.
} 
same dimensions, and with the problem statements written in Sumerian and their resolutions in Akkadian.

\section{A catalogue: the masters classify, order and arrange}

Another tablet, C (YBC 4657), contains the problem statements found in procedure texts A and $\mathrm{B}$ and in the same order. Tablet $\mathrm{C}$, also a type $\mathrm{S}$, is kept at Yale and was probably bought at the same time from the same dealer. Tablet $\mathrm{C}$ contains a list of 31 problem statements written in Sumerian, all on the excavation of a trench. But, contrary to A and B, it does not show the resolution procedures; only the answer to the question.

As noted in the introduction, the problem statement lists of the type found on tablet $\mathrm{C}$ are called "catalogues" by specialists ${ }^{31}$. Currently 10 catalogues of mathematical problems are known to us: the 8 kept at Yale are of unknown provenance; the two at the Louvre come from Susa. The catalogues have the following peculiarities: they are lists of problem statements with no indication of how to resolve them; they are nearly entirely written in Sumerian ideograms, they are thematically homogenous and they finish with a colophon giving the number, and sometimes, the theme of the problem statements. The thematic unity of the catalogues is underlined by the fact that the theme is always indicated at the beginning of each section by the use of a kind of key word in the role of a tag: trenches $\left(\mathrm{ki}^{-} \mathrm{la}_{2}\right)$, fields $\left(\mathrm{a}-\mathrm{s} \mathrm{a}_{3}\right)$, canals $\left(\mathrm{pa}_{5^{-}}\right.$ sig), weights of stone $\left(\mathrm{na}_{4}\right)$, and by the fact that this tag is often repeated in the colophon.

Tablets A, B and C are therefore very closely related and very probably come from the same site $^{32}$. Their characteristic typology leads them to be linked to the same, probably quite advanced, level of mathematics training. Why then do we find, in the same context, two different categories of texts for the same problems, one with resolution procedures and one without? What is the relationship between the procedure texts and the catalogues? Were the procedure texts derived from the catalogues or the catalogues derived from the procedure texts? And what does this relationship tell us about the respective functions of both categories of texts?

A first hypothesis is that the catalogue was a type of guide used by a master and the procedure texts derived from it: the problem statements were taken from the catalogue, then resolved, for example, by a student. It would be a relationship between a "master text" and extracts as often found in the school archives for Sumerian literary texts (see, for example the case of the hymn to Lipit Eshtar quoted above and the corresponding bibliography). However, the overall structure of catalog $\mathrm{C}$ lacks the coherence of a literary text.

The first 8 problem statements in catalogue $\mathrm{C}$ form a coherent group, which is exactly that found on tablet $\mathrm{A}$.

Another hypothesis emerges when examining the overall structure of the texts. Catalogue $\mathrm{C}$ is in fact composed of several juxtaposed groups, as highlighted by Neugebauer and Sachs $(1945,74)$.

\footnotetext{
${ }^{31}$ The name comes from J. Friberg and from J. Høyrup (Høyrup 2001, 8 note 13).

${ }^{32}$ The three texts are published together in the section by Neugebauer and Sachs $(1945,66 \mathrm{ss}$.), which underlines: "These three texts form a closely knit group." (ibib, 73). However, the question of whether procedure texts derive from the catalogues (or vice versa) is not addressed in MCT nor indeed is the issue of the possible difference in function between procedure texts and catalogues.
} 
The next problem statement in catalogue C (9-12) forms a second group made up of variants that involve only the dimensions of the trench (length, width, depth, base and volume) After producing four problem statements with circular permutations of these parameters (9-12), the scribe introduces into the data, linear combinations of length and width (13-14), then the sum of the base and the volume (15-16), and at the same time a linear length and width combination on one hand, and the sum of the base and the volume (17-18) on the other. This second group forms, like the first, a systematic, coherent whole that increases progressively in difficulty and finishes with quadratic problems.

The next 3 problem statements (19-20) are variants using the same parameters as the second group, but they lead to the use of different procedures (they come down to linear systems). The fourth group (22-28) amount to problem statements similar to those of the first group, but involve a large number of parameters: the dimensions of the trench, the daily wage, the daily task, the number of workers and, what is more, the number of working days. These two groups form a body of problems of increasing complexity, describing a wide range of linear problems. This is the coherent whole found on tablet B.

The 2 problems after that lead to quadratic systems similar to those at the end of the first group. The last problem statement is identical to the first (1), but the numeric data differs from the rest of the tablet as this time, the trench has a square section. These three sections (29-31) are somewhat disparate, and do not appear to form a coherent group.

The tablet ends with a colophon which indicates: "31 trench problems".

\section{Procedure and catalogue texts}

In table 4 below the different $\mathrm{C}$ catalogue groups and corresponding $\mathrm{A}$ and $\mathrm{B}$ texts are summarized $^{33}$ :

\footnotetext{
${ }^{33}$ For more details, see (Neugebauer and Sachs 1945, 74 ; Proust forthcoming.
} 


\begin{tabular}{|c|c|c|c|c|}
\hline $\begin{array}{l}\text { Gr } \\
\text { ou } \\
\text { ps }\end{array}$ & Section of $\mathrm{C}$ & Data & Mathematical content & $\begin{array}{l}\text { Correspond- } \\
\text { ing proce- } \\
\text { dure text }\end{array}$ \\
\hline \multirow[b]{2}{*}{1} & $1-6$ & $\begin{array}{l}\text { Trench dimensions, wages, number of work- } \\
\text { ers }\end{array}$ & Linear problem & \multirow[b]{2}{*}{ A } \\
\hline & $7-8$ & $\begin{array}{l}\text { idem } \\
\text { including: linear combinations of length and } \\
\text { width }\end{array}$ & Linear- Quadratic system & \\
\hline \multirow{3}{*}{2} & $9-12$ & Trench dimensions & Linear problem & \\
\hline & $13-14$ & $\begin{array}{l}\text { idem } \\
\text { including: linear combinations of length and } \\
\text { width }\end{array}$ & Linear- Quadratic system & \\
\hline & $15-18$ & $\begin{array}{l}\text { idem } \\
\text { including: sum of the base and the volume }\end{array}$ & Linear- Quadratic system & \\
\hline 3 & $19-21$ & $\begin{array}{l}\text { Trench dimensions } \\
\text { including: linear combinations of length and } \\
\text { width }\end{array}$ & Linear system & \multirow[t]{2}{*}{$\mathrm{B}$} \\
\hline 4 & $22-28$ & $\begin{array}{l}\text { Trench dimensions, wages, number of work- } \\
\text { ers, length of time worked }\end{array}$ & Linear problem & \\
\hline 5 & $29-30$ & $\begin{array}{l}\text { Trench dimensions, wages, number of work- } \\
\text { ers, length of time worked including: linear } \\
\text { combinations of length and width }\end{array}$ & Linear- Quadratic system & \\
\hline \multirow[t]{2}{*}{6} & 31 & $\begin{array}{l}\text { Trench dimensions, , wages, number of } \\
\text { workers }\end{array}$ & Linear problem & \\
\hline & Colophon & "31 trench problems" & & \\
\hline
\end{tabular}

Table 4: Problem groups in catalogue $\mathrm{C}$

All catalogue $\mathrm{C}$ problem statements are homogeneous from a thematic point of view: all focus on the problems of a trench, all begin with the same formula "a trench" ( $\mathrm{ki}-\mathrm{la} 2)$, the dimensions of the trench are the same in all the texts (except the last problem statement). But over the 31 problems there is no regular progression in the methods brought into play, nor systematic classification. However, there are clearly differentiable subgroups that are highly coherent and show clear internal progression. Problems 1-8 in group 1 (see table 4), found in the tablet containing A procedures, show a clear didactic progression. It is the same for Group 2, for which the associated procedures have not been found. Problems 19-28 of groups 3 and 4, found in the tablet containing the B procedures, form a mathematically homogenous whole and focus on linear situations.

The relationship between the catalogue and the procedure texts is therefore probably the opposite of what was assumed above: the catalogue is a kind of compilation made up of several pieces of pre-existing procedure texts. The function of such catalogues in this case remains unclear. It could, for example, be related to the establishment and institutionalization of an advanced mathematical training curriculum. It is possible that setting down this curriculum in writing went hand in hand with the development of the first libraries ${ }^{34}$. This would be a phenomenon similar to that described by Philippe Clancier for the "Manual of the Exorcist", in, it is true, a quite different context (see ch. $\mathrm{xxx}$ ).

In this section, we have seen a sample of texts clearly linked to education, but in different ways for the procedure texts and catalogues. These are mainly texts written on type S tablets, i.e. tablets, which at Nippur and probably throughout southern Mesopotamia in the Old Babylonian period, were used in a stage between basic education and professional scholarliness. Some of these texts appear to result from the training of students in problem-solving (procedure texts A and B). Others, the catalogues, could be compilations bringing together a vast repertoire of problems drawn from several different procedure texts. These compilations could

\footnotetext{
${ }^{34}$ (Glassner 2009).
} 
have been developed by masters to streamline the organization of the mathematical training curriculum, and maybe to classify and archive educational texts, thus constituting the first libraries.

Teaching, classifying and archiving figure among the possible objectives pursued by the authors of the procedure texts and catalogues analyzed here. The example of the "mathematical series texts" presented in the third part testifies that the scribal school masters could also develop projects not directly linked to their teaching activities.

\section{3- Texts written by masters for their peers}

Mathematical series texts (i.e. written on several numbered tablets - see introduction) form a small corpus comprising around 20 tablets. The majority are at Yale University, but examples are also kept in Berlin, Paris and Chicago ${ }^{35}$. These tablets contain long lists of problem statements (more than 1500 in total). Their geographical provenance is unknown, and there is no archeological contextual data relating to them. The corpus of mathematical texts arranged in series is remarkably homogenous; it presents the following characteristics: 1) they are multicolumn tablets; 2) the tablet numbers in the series are recorded in the colophon; 3 ) the colophon also contains the number of problem statements written on the tablet; 4) the writing consists only of Sumerian ideograms; 5) no indication for the resolution of the problems is given; 6) each list is on a single theme (e.g. fields, or canals, or bricks); 7) the style is extremely concise and the lists highly complex. Based on this brief description, one might think that the series texts are quite similar to the catalogues: features 3 to 6 listed above are indeed shared by both categories of texts. In fact, Neugebauer and Sachs considered that there was nothing to differentiate the series texts from other mathematical texts, and there was no justification in giving the series texts a specific name:

Several of the texts which present large numbers of problems without giving answers bear colophons giving the tablet a serial number. This gave rise to the name "Series Texts" used in MKT for this whole group of tablets. We think it wise, however, to abandon this name because the new material makes it difficult to define the borders of this group. (Neugebauer and Sachs 1945, 37).

The function of the series texts, therefore, should be no different from that of the catalogues. For Neugebauer and Sachs, the series texts were repertoires of teaching exercises, an opinion that was regularly taken up later in the historiography. Here is what Neugebauer and Sachs say about the two tablets in the Chicago series:

This text, like the following one, can best be compared to an extensive collection of problems from a chapter of textbook. It is obvious that a collection of this sort was used in teaching mathematical methods. They constitute a large reservoir of problems from which individual problems of any required type (say, speaking from modern point of view, of a certain category of quadratic equation) could be selected." (Neugebauer and Sachs 1945, 116).

\footnotetext{
${ }^{35}$ For the tablets at Yale and in Berlin see Neugebauer 1935-7, I ch. 7 and III p. 27-45; for those in Chicago, see Neugebauer and Sachs 1945, texts T and U and Proust forthcoming-b; for those at the Louvre, see Proust 2009a.
} 
I would like to emphasize here the differences between the series texts and the catalogues and demonstrate that these differences reflect that their authors were not pursuing the same objectives $^{36}$.

The typology of the series tablets is a first clue to take into consideration. Unlike the catalogues, series texts are not written on type $\mathrm{S}$ tablets, which, let us remember, were used in teaching in southern Mesopotamia. Another peculiarity of the series texts lies in the writing techniques used to describe the operations and the parameters; these techniques are evidence of virtuosity not seen in the catalogues. The structure of the problem statements is also quite unique. We have seen that in the case of the catalogues, the lists are essentially built on a set of circular permutations of the parameters. In addition, each problem statement is autonomous in the sense that it contains all the information necessary for the understanding and resolution of the problem. In the case of the series texts, the construction of the lists is only marginally based on circular permutations. The structure is based on a system of linked variations producing an arborescent structure.

To illustrate this process, let us take as example an extract of tablet AO 9071. According to its colophon, this tablet is the seventh in a series and contains 95 problems on the dimensions of a rectangle; the unknowns are the length and width. Problem statement 59 reads:

\section{I added: 45}

(ba-zi-ma 45)

It is clear that such a problem statement is incomplete and does not contain all the information required to solve the problem. The necessary information is in fact dispersed throughout the previous sections. Once all the information has been recovered, the problem can be represented in modern language by the following linear system, where $\mathrm{x}$ is the length of the rectangle and $\mathrm{y}$ is its width:

$$
\left\{\begin{array}{l}
(3 \times x+2 \times y) \frac{1}{13}+x=40 \\
\left\{\left\langle\left\{[(x+25)+(y+1.30-x)+(x+y+35)] \frac{1}{11}+4 x\right\} \frac{1}{7}+y\right\rangle \times 2 \times \frac{1}{16}-(x+2 y)+x+y+(3 x-2 y)\right\} \frac{1}{7}+(x+y)=45
\end{array}\right.
$$

How can a problem statement so brief represent a problem so complex? The process is as follows: The problem statements are made up of four blocks. Each block undergoes changes. Block 1 (which here corresponds to the first equation in a linear system) undergoes several variations; for each variant in block 1, block 2 undergoes several variations; for each variant in block 2, block 3 undergoes several variations; for each variant in block 3, block 4 undergoes several variations. Thus we obtain a four-level arborescent structure. Information is grafted onto this tree-like structure; its distribution accords the following principle: any information given in one level of the arborescence is omitted from statements in the levels which derive from it. As a result, when reading one section, the user has to go back in the text to look for information given in the previous sections. In the case of this problem statement, the information is found at four different points: in sections 35, 50, 57 and 59.

The following diagram shows how the information referred to in problem statement 59 is distributed in the text.

\footnotetext{
${ }^{36}$ I shall confine myself here to very general remarks about the series texts. Entering into the detail of the texts largely goes beyond the scope of this contribution. For more information, see (Proust 2009a, Proust forthcoming$a$, Proust forthcoming-b).
} 


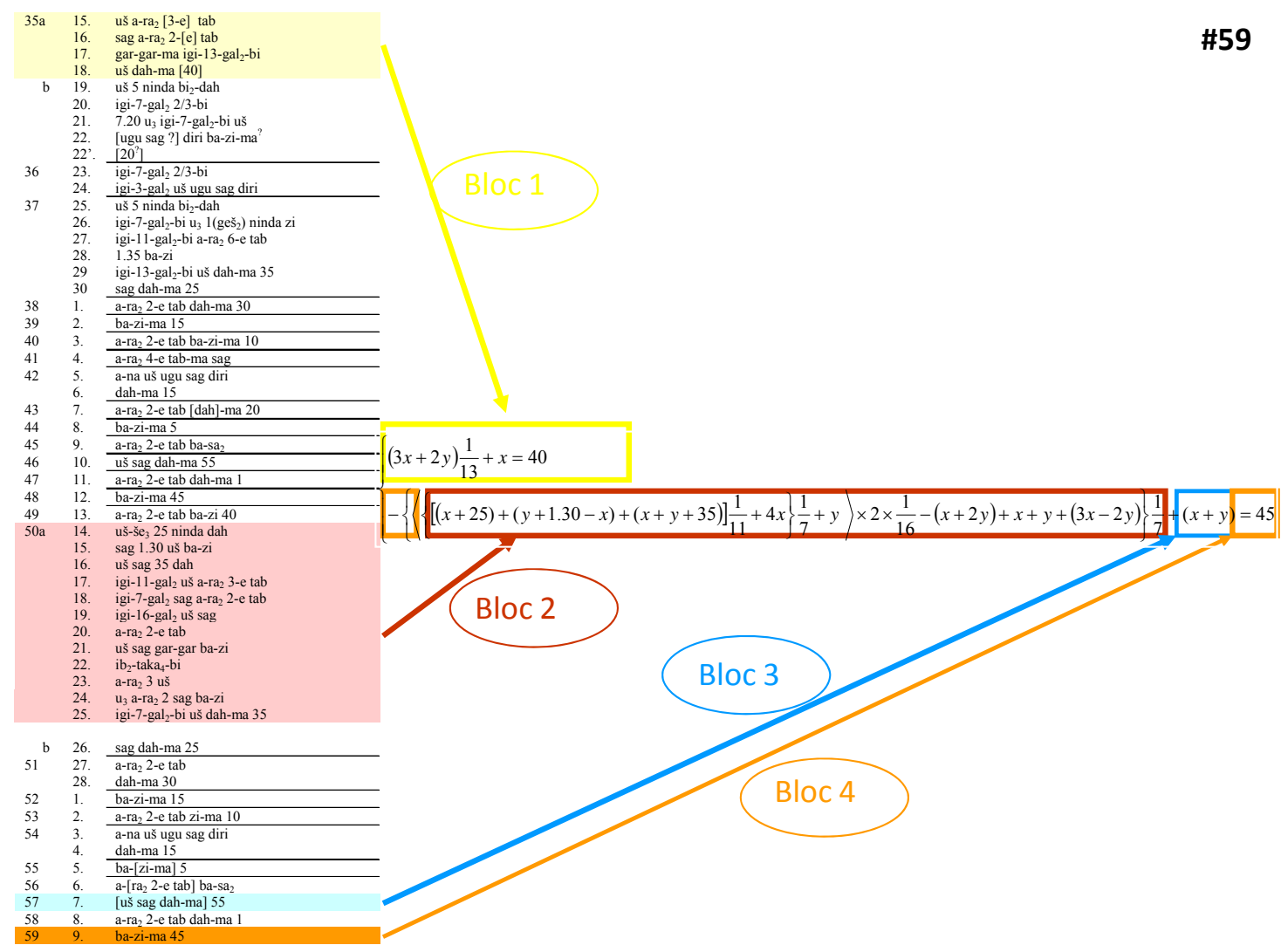

Table 5: distribution of the information on series tablet AO 9071

Add text reduction processes to these structural elements, such as the omission of grammatical particles, and the representation of complex expressions by an ideogram and we obtain a highly technical text asking a lot of expertise of the reader.

Another major difference between the catalogues and the series texts concerns the mathematical content of the problem statements. The problem statements in catalogues are regular, in the sense that they are widely represented in cuneiform mathematics. The parallels between the two procedure texts $\mathrm{A}$ and $\mathrm{B}$ and the catalogue $\mathrm{C}$ are a striking illustration of this. Conversely, the problem statements set out in the series texts are, for the most part, unique in the known mathematical corpus. One can even wonder if some of them were ever intended to be resolved. The example given above (\#59 from AO 9071) is an example of this. No known Old Babylonian source bears witness to the existence of methods to reduce such a problem. Some simple (and very laborious) reductions are documented in some texts from Susa ${ }^{37}$. But, assuming that these reduction techniques were also carried out in Mesopotamia, they remain insufficient to overcome many of the problems found in the series texts. One can argue this is an ex silentio argument, and that in the future procedure texts relating to the series texts may be discovered. However, it is clear that this will not be the case for certain problem statements in the series texts, namely those that go back to fourth or fifth degree problems that cannot be reduced to lower degrees ${ }^{38}$. It is as if lists were developed in the series texts according to formal rules to produce increasingly sophisticated problem statements, regardless of any educational application linked to learning the resolution of the problems. For the authors, this was

\footnotetext{
37 TMS 7 and 16 (Høyrup 2002, 85, 181).

${ }^{38}$ See for example problems \#35 to 47 of the YBC 4668 series tablet (1935-7 Neugebauer, I, 455-6), which go back to 4 problem levels but are not reducible any further, or indeed problems \#28 YBC to 32 of 4710 (1935-7 Neugebauer, I, 410-1), which go back 5 levels and can not be further reduced.
} 
presumably, an investigation into all the possible ways of creating problem statements. Varying the parameters had a heuristic, not a didactic value as in the procedure texts and the catalogues described in the previous sections of this chapter ${ }^{39}$.

Some considerations on dating complete this contrasting picture. Arrangement in series with colophons is relatively rare in the Old Babylonian period. This textual form appears quite late with divinatory texts. We can presume that the mathematical series texts date from the very end of the first Babylonian dynasty. This hypothesis is shared by J. Høyrup, who comments that this genre of text could only have been developed after the maturation phase of the discipline $^{40}$. The hypothesis of an even later dating, possibly the Kassite period, was put forward by Neugebauer

Together, these elements seem to indicate that the context of the series texts is not that of classic Old Babylonian scribal schools of the southern Mesopotamian plain, and that it therefore differs from the catalogues. It is doubtful that they are repertoires of problems destined to be solved by students. However, they do show extensive reflection on mathematical writing techniques and the structure of problem statements. Their purpose seems to be primarily to improve mathematical language in order to produce the broadest possible range of problems. Such thinking is most probably more connected to the activities of a community of scholars than to needs directly linked to education.

\section{Conclusion}

The different examples analyzed in this contribution show the diversity of situations in which mathematical texts were produced in scribal schools: some texts were written by beginnerlevel or more advanced apprentice scribes, others by masters; some texts used in teaching were specifically designed for this objective, others not; some tablets appear to be textbooks, but in fact meet objectives other than those of education. Thus "educational context" is a vague term, covering a wide spectrum of different situations, uses and objectives. The activities of scribal school masters were made up of two parts, teaching and communication between peers. These two components are strongly interconnected, and yet they do not completely overlap. Developments in mathematics are the result of both the activity of teaching and interaction within a community of scholars.

In the Old Babylonian period, education went hand in hand with creative activity, supported by a very active milieu. Maybe this environment was more developed in some major centers (Nippur, Ur, Eshnunna, Kish, Susa for example) than in others. The most active centers were able to influence other, less creative ones, where the educational framework was less institutional. The existence of an erudite scribal milieu at Nippur is without doubt, and is likely elsewhere. These scribes conferred together (Villard 1997) and traveled (Charpin 1992). A network of long-distance links between the scribes seems to have existed. Two clues demonstrate this: these are, on one hand, the uniformity of the content of Ancient Near Eastern (Mesopotamia, Elam, Syria, Ugarit, etc.) school tablets, and on the other hand the disparity between the content taught and local practice (Mari). These links between scribes, even far apart

\footnotetext{
${ }^{39}$ It is interesting to note that the function of the sets of parameters in the collections of problems is not always the same. See for example cases described in Section A.. Volkov (ch. xxx), where the parameter variations seem to have both a didactic and a heuristic function.

40 "the sophistication of many of the series texts - regarding mathematical substance as well as the pluridimensional variation of statements - shows them to belong to a more mature phase of scholastization than the Eshnunna corpus" (Høyrup 2002, 351).
} 
from each other, appear to have been stronger than the short links between scribal schools and local administration.

Through the examples presented in this chapter, I wanted to draw attention to the trap presented by words like "scribal school" and "school text", whose implicit meanings heavily influence interpretations. Old Babylonian scribal schools were the places where the learning of cuneiform writing and arithmetic took place, but they were often also intellectual centers. Some texts, written by the students themselves clearly reflect elementary teaching activities, others, written by the masters, bear witness to the activity of teaching, while others still show communication between scholars. These are the three examples which have been illustrated in this chapter. But not all currently-known mathematical texts fit easily with these examples. Many of them, either because their archaeological context as been lost or is poorly known, or because the archaeological data does not say enough, are more difficult to interpret. Were they written by advanced students or by masters? Who did they address? Do they contain innovations or are they just transcriptions of the master's "words"? Are they repertoires of exercises, or elaborations designed to generalize or justify mathematical results? The available data rarely allows answers to all these questions at the same time. The texts should be examined on a case by case basis. If we examine all the different types of evidence provided by the mathematical documents, for example the typology of the tablets, the layout of the text, the choice of notation for the metrological and numerical graphemes, the language and the terminology, and the writing techniques, we can find answers or at least partial answers to some of these questions. What I would like to emphasize is that these answers are extremely diverse. In only seeing repertoires of teaching exercises in erudite cuneiform mathematical texts, we lose sight of the originality and remarkable inventiveness reflected by these mathematical texts produced more than 4000 years ago.

*** ajouter données de Delnero 2011 (Inana \& Ebih)*** 
Plate
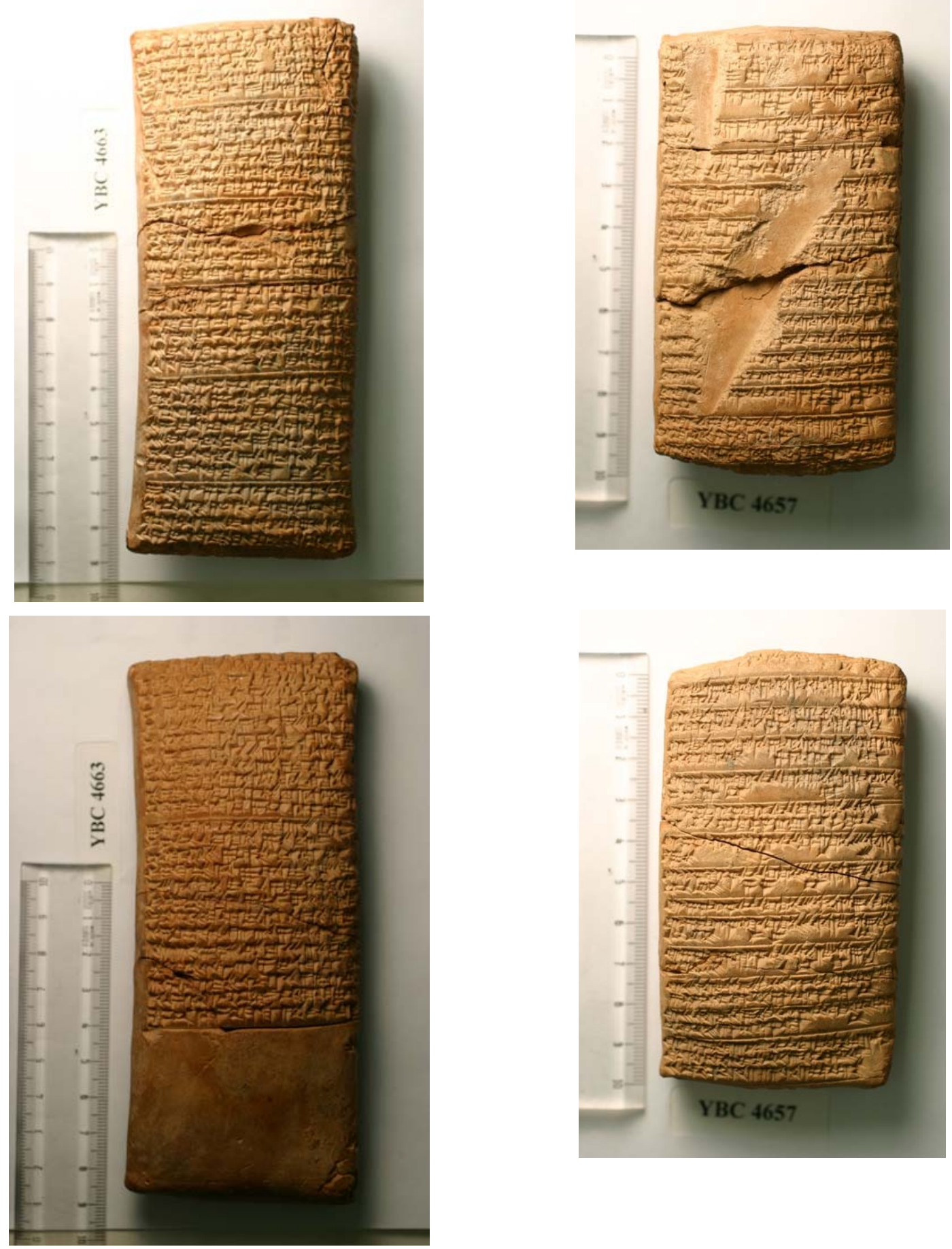

Figure 1 - Procedure text, type S tablet (YBC 4663, Yale University)

Figure 2 - Catalogue, type $\mathrm{S}$ tablet (YBC 4657, Yale University) 

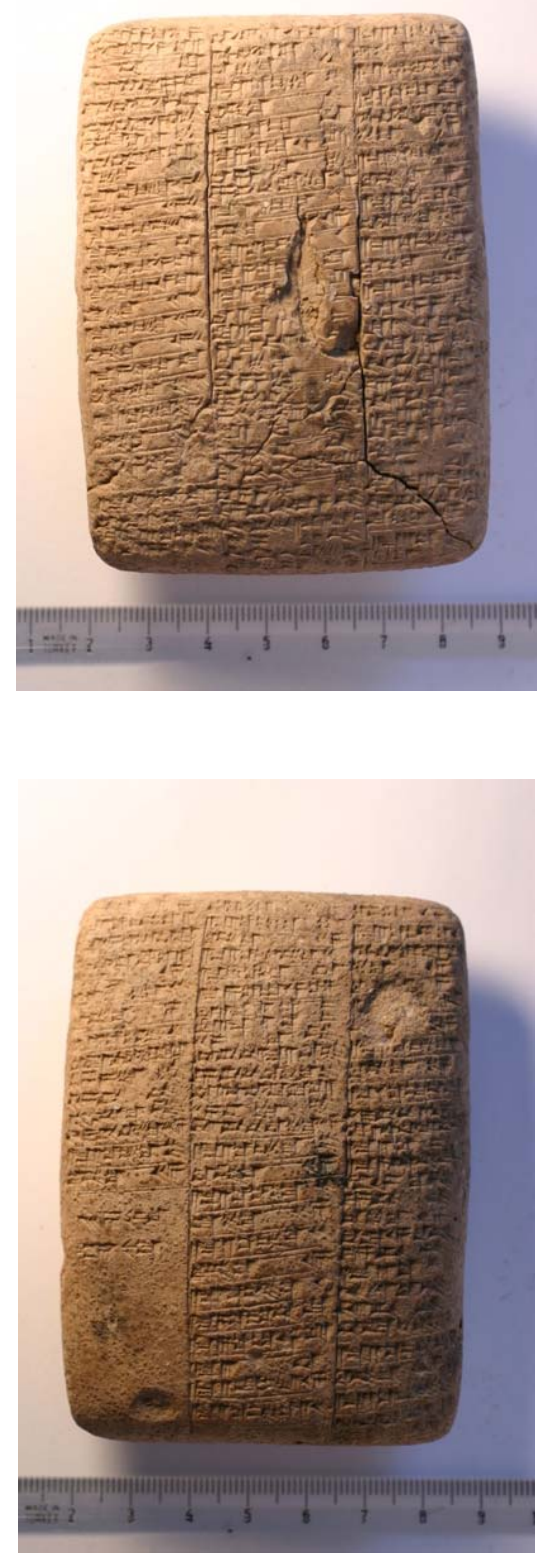

Figure 3 - Series text, type $M$ tablet (AO 9071, Le Louvre Museum) 


\section{Bibliography}

Al-Rawi, F. and Roaf, M. (1984) Ten Old Babylonian mathematical problems from Tell Haddad, Himrin, Sumer, 43, pp. 175-218.

Baqir, T. (1950a) An important mathematical problem text from Tell Harmal, Sumer, 6, pp. 39-54 et 130-148.

Baqir, T. (1950b) Other mathematical problems from Tell Harmal, Sumer, 2, pp. 123.

Baqir, T. (1951) Some more mathematical texts from Tell Harmal, Sumer, 7, pp. 28-45.

Baqir, T. (1962) Tell Dhiba'i: New mathematical texts, Sumer, 18, pp. 11-14.

Bernard, A. and Proust, C. (2008) La question des rapports entre savoir et enseignement dans l'antiquité, in: L. Viennot (Ed) Didactique, épistémologie et histoire des sciences. Penser l'enseignement (Paris PUF, collection Science, histoire et société (dir. D. Lecourt)).

Bruins, E. and Rutten, M. (1961) Textes mathématiques de Suse (Paris, Geuthner).

CDLI (website) Cuneiform Digital Library Initiative: http://cdli.ucla.edu/

Charpin, D. (1992) Les malheurs d'un scribe ou de l'inutilité du sumérien loin de Nippur, in:

M. deJong Ellis (Ed) Nippur at the Centennial. Papers Read at the 35e Rencontre Assyriologique Internationale, Philadelphia, 1988, Vol. 14 (Philadelphia, University Museum / Babylonian Section).

Friberg, J. (2000) Mathematics at Ur in the Old Babylonian period, Revue d'Assyriologie, 94, pp. 98-188.

Gasche, H., Armstrong, J.A., Cole, S.W. and Gurzadyan, V.G. (1998) Dating the Fall of Babylon. A Reappraisal of Second-Millenium Chronology (A Joint Ghent-ChicagoHarvard Project) (Ghent et Chicago,

George, A.R. (2005) In Search of the é.dub.ba.a: The Ancient Mesopotamian School in Literature and Reality, in: Y. Sefati, P. Artzi, C. Cohen, B.L. Eichler and V.A. Hurowitz (Eds) "An Experienced Scribe Who Neglects Nothing". Ancient Near Eastern Studies in Honor of Jacob Klein (Bethesda, CDL Press).

Glassner, J.-J. (2009) Ecrire des livres à l'époque paléo-babylonienne: le traité d'extispicine, Zeitschrift für Assyriologie und Vorderasiatische Archäologie, 99(1), pp. 1-81.

Goetze, A. (1945) The Akkadian dialects of the Old-Babylonian mathematical texts, in: O. Neugebauer and A.J. Sachs (Eds) Mathematical Cuneiform Texts, Vol. 29 (New Haven, AOS \& ASOR).

Goetze, A. (1951) A mathematical compendium from Tell Harmal, Sumer, 7, pp. 126-155.

Hilprecht, H.V. (1906) Mathematical, Metrological and Chronological Tablets from the Temple Library of Nippur (Philadelphia, University of Pennsylvania).

Høyrup, J. (2002) Lengths, Widths, Surfaces. A Portrait of Old Babylonian Algebra and its Kin (Berlin \& Londres, Springer).

Michalowski, P. (1987) Charisma and control: on continuity and change in early Mesopotamian bureaucratic systems, in: M. Gibson and R.D. Biggs (Eds) The organization of power, aspects of bureaucracy in the near east, Vol. 46 (Chicago, The Oriental Institute of the University of Chicago).

Neugebauer, O. (1935-7) Mathematische Keilschrifttexte I-III (Berlin, Springer).

Neugebauer, O. and Sachs, A.J. (1945) Mathematical Cuneiform Texts (New Haven, AOS \& ASOR).

Neugebauer, O. and Sachs, A.J. (1984) Mathematical and Metrological Texts, Journal of Cuneiform Studies, 36, pp. 243-251.

Proust, C. (2005) A propos d'un prisme du Louvre: aspects de l'enseignement des mathématiques en Mésopotamie, SCIAMVS, 6, pp. 3-32.

Proust, C. (2007) Tablettes mathématiques de Nippur (Istanbul, IFEA, De Boccard). 
Proust, C. (2008a) Quantifier et calculer: usages des nombres à Nippur, Revue d'Histoire des Mathématiques, 14(2), pp. 143-209.

Proust, C. (2008b) Tablettes mathématiques de la collection Hilprecht (Leipzig, Harrassowitz).

Proust, C. (2009a) Deux nouvelles tablettes mathématiques du Louvre : AO 9071 et AO 9072, Zeitschrift für Assyriologie und Vorderasiatische Archäologie, 99(2), pp. 167-232.

Proust, C. (2009b) Numerical and metrological graphemes: from cuneiform to transliteration, Cuneiform Digital Library Journal, 2009:1, pp. $<$ http://www.cdli.ucla.edu/pubs/cdlj/2009/cdlj2009_2001.html $>$.

Proust, C. (forthcoming-a) L'art des listes dans les mathématiques cunéiformes. Approche linguistique, épistémologique et historiographique des listes d'équations (Mésopotamie, début du deuxième millénaire avant notre ère)

Proust, C. (forthcoming-b) A tree-structured list in a mathematical series text from Mesopotamia, in: K. Chemla and J. Virbel (Eds) Introduction to textology via scientific writings

Robson, E. (2001) The Tablet House: A Scribal School in Old Babylonian Nippur, Revue d'Assyriologie, 95, pp. 39-66.

Robson, E. (2002) More than metrology: mathematics education in an Old Babylonian scribal school, in: J.M. Steele and A. Imhausen (Eds) Under One Sky. Astronomy and Mathematics in the Ancient Near East, Vol. 297 (Münster, Ugarit-Verlag).

Robson, E. (2008) Mathematics in Ancient Iraq: A Social History (Princeton, Princeton University Press).

Thureau-Dangin, F. (1936) Textes mathématiques babyloniens, Revue d'Assyriologie, 33-2, pp. 65-84.

Tinney, S. (1998) Texts, Tablets, and Teaching: Scribal Education in Nippur and Ur, Expedition, 40, pp. 40-50.

Tinney, S. (1999) On the curricular setting of Sumerian literature, Iraq, 61, pp. 159-172.

Vanstiphout, H.L.J. (1979) How did they learn sumerian?, Journal of Cuneiform Studies, 31, pp. 118-126.

Veenhof, K.R. (Ed.) (1986) Cuneiform Archives and Libraries. Papers read at the 30ème Rencontre Assyriologique Internationale (Leiden,

Veldhuis, N. (1997) Elementary Education at Nippur, The Lists of Trees and Wooden Objects(Groningen, University of Groningen).

Villard, P. (1997) L'éducation d'Aššurbanipal, Ktèma, 22, pp. 135-149. 